\title{
IMPROVING THE BREAD QUALITY OF SUNI-BUG DAMAGED WHEAT FLOURS BY SOURDOUGH BREADMAKING AND LIQUID RYE SOUR
}

\author{
G. ÖZÜLKÜa and D. SivRi ÖZAY ${ }^{b *}$

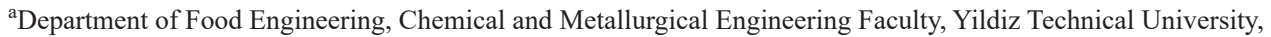 \\ Istanbul. Turkey \\ ${ }^{\mathrm{b}}$ Department of Food Engineering, Engineering Faculty, Hacettepe University, Ankara. Turkey
}

(Received: 10 September 2019; accepted: 5 February 2020)

\begin{abstract}
The breadmaking quality of bug-damaged wheat flours with high protease activity (HPAWF) and low protease activity (LPAWF) was attempted to be improved by using sourdough (prepared by L. plantarum (SD1) and L. sanfrancissensis (SD2)) and liquid rye sour (LRS) in this study. The effects of sourdoughs (20 and 40\%) and LRS (1 and $2 \%$ ) on the protease activity of the HPAWF were determined by SDS-PAGE. Protease activity of HPAWF decreased with the addition of $40 \%$ SD1, 20\% SD2, and both levels of LRS (1 and 2\%) compared to a control sample. The HPAWF bread samples produced with LRS ( 1 and $2 \%$ ) had higher volume $(\mathrm{P}<0.05)$ and bread quality as compared to sourdough applications. LPAWF bread sample was comparable with those of $40 \%$ SD2 added sample in terms of volume and hardness $(\mathrm{N})$ values $(\mathrm{P}>0.05)$, while SD1 addition caused quality losses. The overall results suggested that addition of $2 \%$ LRS had promising results for improving bread quality flours that were damaged by suni-bug at low levels.
\end{abstract}

Keywords: high protease activity wheat flour, sourdough, liquid rye sour, bread quality

Some heteropterous insects (Eurygaster spp., Aelia spp.) called as suni-bug or wheat bug cause preharvest damage to wheat. They attack developing wheat kernels and leave their salivary secretions containing proteolytic enzymes in the grain. Damaged wheat results in a sticky dough and bread with low volume with poor crust and crumb (KARABABA \& OzAN, 1998).

The bug protease is active over a broad $\mathrm{pH}$ range $(\mathrm{pH} 3.0-11.0)$ and has maximum activity at $\mathrm{pH} 8.5$. The optimum temperature of this protease is $35^{\circ} \mathrm{C}$ (SIVRI \& Köksel, 2000). Heat treatment at $70^{\circ} \mathrm{C}$ for $2.0-3.0 \mathrm{~min}$ and hot tempering applications at $70{ }^{\circ} \mathrm{C}$ for $30 \mathrm{~min}$ improved the quality of suni-bug damaged wheats (Diraman \& DEMIRCI, 1997). Some natural and synthetic inhibitors, chemicals $\left(\mathrm{NaCI}, \mathrm{CaCI}_{2}, \mathrm{KH}_{2} \mathrm{PO}_{4}\right.$, organic acids), or additives (L-ascorbic acid, transglutaminase, glucose oxidase) in the bread formula resulted in a decrease in the proteolytic activity; and short-time fermentation and low temperature processing improved baking quality (Diraman et al., 1998; SivRI \& KÖKSEL, 2002; OlanCA \& SiVRI ÖZAY, 2015).

Sourdough bread making is an ancient method to improve bread quality and increase the shelf-life of bread (ARENDT et al., 2007). L. sanfranciscensis, L. plantarum, and S. cerevisiae are the most frequently isolated species from sourdough, and they are positively related to the sensory quality of sourdough breads (GoBbetTI et al., 2005). Liquid rye sour is a kind of

\footnotetext{
* To whom correspondence should be addressed.

Phone: +90 312 2996211; fax: +90 312 2992123; e-mail: sivri@hacettepe.edu.tr
} 
additive used in the bakery industry in order to increase the acidity of the dough and bread with a specific light sour taste and pleasant aroma (DECOCK \& CAPPELLE, 2005).

In this study, sourdough as an ancient technology and liquid rye sour were firstly used in bread formula in order to increase baking quality of bug-damaged wheat flours. Sourdoughs were prepared with L. plantarum (SD1) and L. sanfranciscensis (SD2), and liquid rye sour and proteolytic activity were monitored by SDS-PAGE. The applications having low protease activity were performed for high protease activity flour HPAWF in baking studies. In addition, effects of these applications were repeated for low protease activity flour (LPAWF).

\section{Materials and methods}

\subsection{Materials}

A sound (undamaged) wheat cultivar was obtained from Field Crops Central Research Institute, Ankara, Turkey, and a suni-bug damaged wheat cultivar was obtained from the Plant Protection Research Station, Diyarbakır, Turkey. Sound wheat and suni-bug damaged wheat samples were milled in a Buhler laboratory mill (MLU 202, Uzwil, Switzerland) to obtain straight-grade flour with the yields of $65 \%$ and $60 \%$, respectively (Approved Method 26-21, AACC International 2000). High protease activity wheat flour (HPAWF) and low protease activity wheat flour (LPAWF) samples were prepared by blending of $50 \%$ sound wheat flour (SWF) $+50 \%$ suni-bug damaged flour and 75\% SWF $+25 \%$ suni-bug damaged flour, respectively. L. sanfranciscensis (CIP 103252) and L. plantarum (CIP 102021) were purchased from the Pasteur Institute (France) and used for preparing the sourdough. Liquid rye sour (LRS) was donated by Ireks Food Industry (Turkey).

\subsection{Flour analyses}

American Association of Cereal Chemists (AACC) Standard Methods were used for determining moisture (No: 44-15A), ash (No: 08-01), protein (No:46-30), and wet gluten contents (No: 38-11), farinograph properties (No:54-21), Zeleny sedimentation (No: 5660A), and falling number values (No: 56-81B) (AACC, 1990). The modified sedimentation value was used to determine suni-bug damage levels (KöKSEL et al., 2002). Alveoconsistograph (Chopin, France) and Mixolab (Chopin, France) analyses were also done according to AACC Method No: 54-30A and AACC 54-60.01, respectively (AACC, 2010). Each analysis was performed as duplicate.

\subsection{Inoculum preparation}

All strains were stored at $-25{ }^{\circ} \mathrm{C}$ in de Man Rogosa Sharpe (MRS) broth (Merck) containing $30 \%(\mathrm{v} / \mathrm{v})$ glycerol as a cryoprotectant. Prior to inoculation into the bread formulation, the strains were propagated twice in $10 \mathrm{ml}$ of MRS broth and incubated at $30^{\circ} \mathrm{C}$ for $\mathrm{L}$. sanfranciscensis and $37^{\circ} \mathrm{C}$ for L. plantarum overnight. The fresh starter culture inoculum was obtained by centrifugation $\left(9000 \times g, 10 \mathrm{~min}, 4^{\circ} \mathrm{C}\right)$ of the second overnight culture $\left(10^{8}\right.$ CFU ml-1). 


\subsection{Sourdough preparation}

Sixty grams of flour, $110 \mathrm{~g}$ of sterile deionised water, and $10 \mathrm{ml}$ of bacterial suspension with the cell density of $10^{8} \mathrm{CFU} \mathrm{ml}^{-1}$ were mixed to obtain faster acidification with the dough yield (DY, dough weight $\times 100$ / flour weight) of 300 . Fermentation was carried out at $37^{\circ} \mathrm{C} 24 \mathrm{~h}$ for L. plantarum (SD1) and $30^{\circ} \mathrm{C} 24 \mathrm{~h}$ for L. sanfranciscensis (SD2). The $\mathrm{pH}$ of the sourdough was measured using a Hanna Instruments 221 (Romania) device.

\subsection{Sample preparation for electrophoresis}

High protease activity wheat flour (HPAWF) was prepared by blending of sound (undamaged) wheat flour $(50 \%)$ and suni-bug damaged wheat flour $(50 \%)$. Sourdough $(20 \%$ and $40 \%)$ or LRS (1 and 2\%) were added to the HPAWF (50 g) and the samples were mixed for the dough developing time as determined by a farinograph. The prepared doughs were separated into two pieces. One of the dough pieces was directly lyophilised. The other piece of dough was fermented at $30{ }^{\circ} \mathrm{C}$ and $85 \%$ humidity for $115 \mathrm{~min}$ before lyophilisation.

\subsection{Measurement of proteolytic activity}

Sodium dodecyl sulphate polyacrylamid gel electrophoresis (SDS-PAGE) was used to monitor the gluten hydrolysis according to the procedure described by NG and BusHuK (1987). Glutenin was extracted from the lyophilised dough samples according to the method described by Fu and SAPIRSTEIN (1996).

\subsection{Breadmaking procedure}

AACC method (No 10-11) with some modifications according to a Turkish bread formulation was used in the baking experiments (AACC, 1990). In this formulation, $100 \mathrm{~g}$ flour (dry basis), $25 \mathrm{ml} 8 \%$ yeast solution, and $25 \mathrm{ml} 6 \% \mathrm{NaCl}$ solution were mixed (Kitchen aid, USA) with additional water as determined by a farinograph. The flour was replaced by HPAWF or LPAWF.

\subsection{Bread evaluation}

The bread volume was measured by using the rapeseed displacement method. Texture analysis was carried out by using a Chatillon TAPlus machine (Lloyd Instruments, UK) with a $5 \mathrm{~kg}$ load cell by using a $35 \mathrm{~mm}$ diameter aluminium probe. The test speed was $55 \mathrm{~mm}$ $\mathrm{min}^{-1}$. Each sample was sliced to $12.5 \mathrm{~mm}$ thickness, and for two slices the force $(\mathrm{N})$ required to compress the samples to $25 \%$ was measured. Hardness value $(\mathrm{N})$ was evaluated. Colour analysis was determined using a Minolta Spectrophotometer CM-3600 d (Japan) according to the CIE L*a*b* system.

\subsection{Statistical analysis}

Experimental procedure used in this study was summarised in Figure 1. The effect of applications on physical quality of bread samples (1 and 2\% LRS, $40 \%$ SD1, $20 \%$ SD2 to HPAWF; $2 \%$ LRS, $40 \%$ SD1 and $40 \%$ SD2 to LPAWF) was statistically evaluated by one way analyses of variance (ANOVA) using SPPS statistical software version 16.0 (2007). Some applications showing no decreasing effect on protease activity were not used for baking experiment. Duncan's test was applied to compare the mean values $\mathrm{P}<0.05$. 


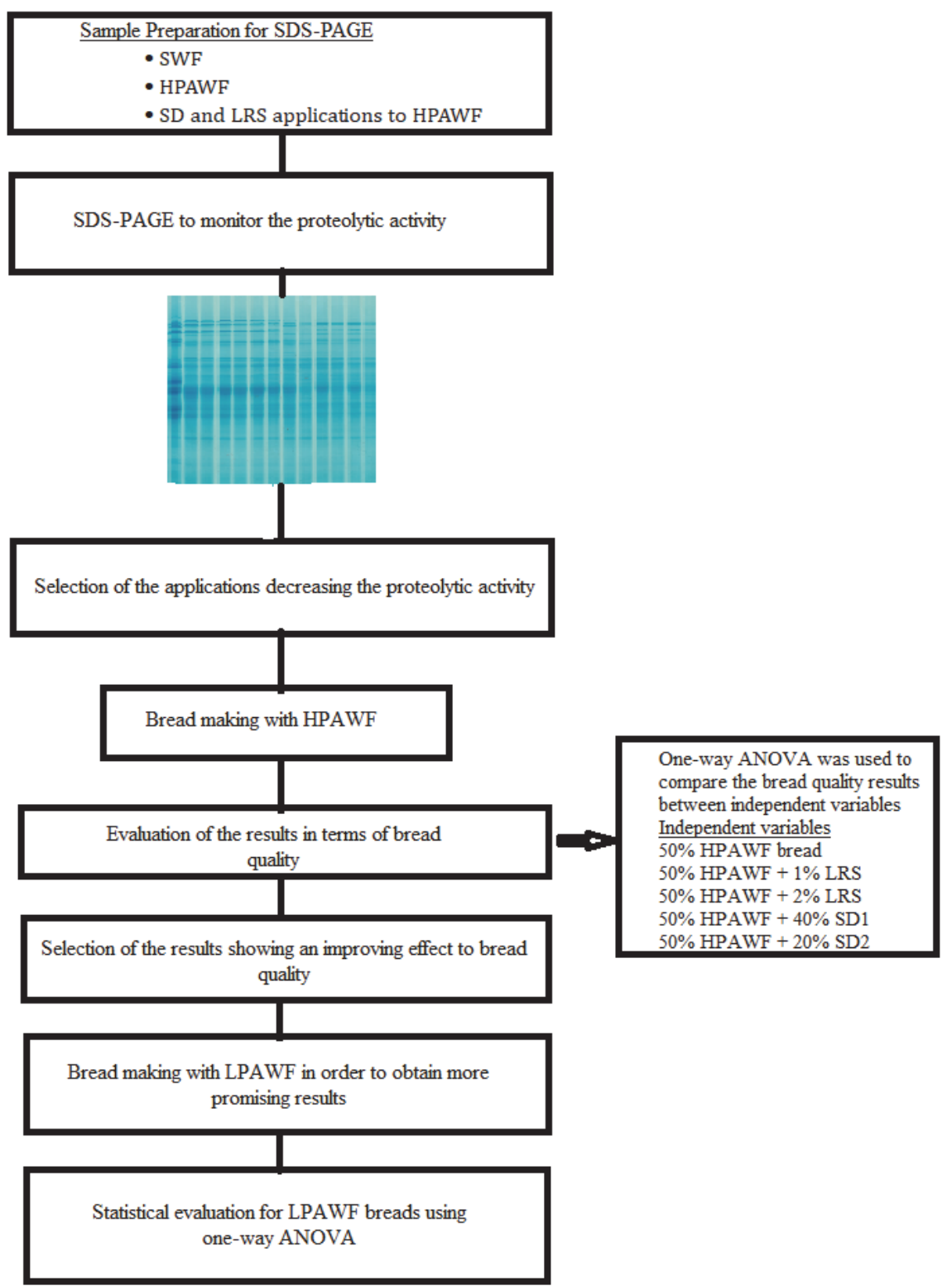

Fig. 1: Experimental procedure

\section{Results and discussion}

\subsection{Chemical and physicochemical properties of flours}

The difference between Zeleny sedimentation and modified sedimentation tests indicated that HPAWF had high protease activity (Table 1). 


\begin{tabular}{lcc}
\multicolumn{3}{c}{ Table 1. Quality characteristics of flour } \\
\hline \multicolumn{2}{c}{ Sound wheat flour (SWF) } & Suni-bug damaged wheat flour \\
\hline Chemical and physicochemical properties & 12.8 & 11.4 \\
Moisture (\%) & 0.57 & 0.61 \\
Ash content (\%, db) & 11.6 & 9.8 \\
Protein content*(\%) & 34 & 23 \\
Zeleny sedimentation value** (ml) & 33 & 7 \\
Modified sedimentation value** (ml) & 470 & 408 \\
Falling number*** (sec) & 32.7 & Cannot be washed \\
Wet gluten content** (\%) & & \\
Farinograph properties & 63.5 & 52.3 \\
Water absorption (\%) & 2.0 & 1.2 \\
Developing time (min) & 1.5 & 1.1 \\
Stability (min) & 50 & 250 \\
Number of kneading tolerance (BU) & 100 & 300 \\
Degree of softening (BU) & & \\
Mixolab properties & 60.0 & 55.70 \\
Water absorption (\%) & 5.4 & 2.03 \\
Stability (min) & 1.1 & 1.14 \\
C1(Nm) & 0.45 & 0.16 \\
C2(Nm) & 1.94 & 1.30 \\
C3(Nm) & 1.81 & 1.67 \\
C4(Nm) & 2.45 & 2.56 \\
C5(Nm) & -0.060 & -0.040 \\
$\alpha$ (Nm/min) & 0.476 & 0.124 \\
B (Nm/min) & 0.008 & 0.018 \\
$\gamma$ (Nm/min) & &
\end{tabular}

$\mathrm{db}$ : dry basis

$*$ : $\mathrm{N} \times 5.7$; **: based on $14 \%$ moisture; $* * *$ : based on $15 \%$ moisture

$\mathrm{C} 1$ : (1st stage, max consistency, $\mathrm{T}=30^{\circ} \mathrm{C}$ ) developing time, water absorption; $\mathrm{C} 2$ : (2nd stage, max consistency, $\mathrm{T}=60{ }^{\circ} \mathrm{C}$ ) protein attenuation; $\mathrm{C} 3$ : $\left(3 \mathrm{rd}\right.$ stage, $\max$ consistency, $\left.=90^{\circ} \mathrm{C}\right)$ starch gelatinisation; $\mathrm{C} 4$ : (4th stage, max consistency, $\mathrm{T}=90{ }^{\circ} \mathrm{C}$ ) amylase activity; $\mathrm{C} 5$ : ( 5 th stage, max consistency, $\mathrm{T}=50{ }^{\circ} \mathrm{C}$ ) retrogradation; $\alpha, \beta, \gamma:$ the resistance of the dough to the kneading at $2 \mathrm{nd}$, 3rd, and 4 th stages

\subsection{Rheological properties of flours}

As expected, SWF has better rheological properties than HPAWF due to having higher water absorption, developing time, stability, lower number of kneading tolerance and degree of softening (Table 1).

$\mathrm{C} 1-\mathrm{C} 5$ and $\alpha, \beta, \gamma$ are the parameters of mixolab. $\mathrm{C} 1$ and $\mathrm{C} 2$ are related to protein quality, whereas $\mathrm{C} 3, \mathrm{C} 4$, and $\mathrm{C} 5$ are related to the starch characteristics. Slopes $\alpha, \beta$, and $\gamma$ are the indicators of protein weakening, starching speed, and enzymatic degradation. C1 represents the maximum point of the first mixing stage at $30^{\circ} \mathrm{C}$. The water absorption value of SWF and HPAWF to reach the $\mathrm{C} 1$ value are $60.0 \%$ and $55.7 \%$, respectively, whereas the stability values are 5.4 and $2.0 \mathrm{~min}$, respectively. At the second stage of mixolab, the dough is heated to $60{ }^{\circ} \mathrm{C}$. Both increasing the dough temperature and kneading decrease the 
consistency of the dough to $\mathrm{C} 2$. This decrease is related to protein weakening, and a higher difference between $\mathrm{C} 1$ and $\mathrm{C} 2$ is a sign of poor-quality flour (KoKseL et al., 2009). Higher differences between $\mathrm{C} 1$ and $\mathrm{C} 2$ in HPAWF than SWF confirmed that HPAWF had low protein quality (Table 1).

\section{3. $p H$ values of sourdough and liquid rye sour}

Incubation conditions were $24 \mathrm{~h}$ at $37^{\circ} \mathrm{C}$ for SD1 (L. plantarum) and $24 \mathrm{~h}$ at $30^{\circ} \mathrm{C}$ for SD2 (L. sanfranciscensis). The $\mathrm{pH}$ of Sourdough 1 was between 3.4-3.7, while the $\mathrm{pH}$ of Sourdough 2 was between 4.0-4.5. The $\mathrm{pH}$ of liquid rye sour was also 2.8-3.2.

\subsection{Effect of sourdough prepared by L. plantarum on electrophoretic patterns of glutenins}

Disappearance or decreasing protein band intensities of the SDS PAGE indicate proteolytic activity. The addition of sourdough prepared by L. plantarum at $20 \%$ and $40 \%$ resulted in no change on the glutenin patterns of sound wheat flour (Fig. 2, lines 5 and 7). It is suggested that $L$. plantarum had no proteolytic activity on glutenins as expected (WeHrLE et al., 1999).

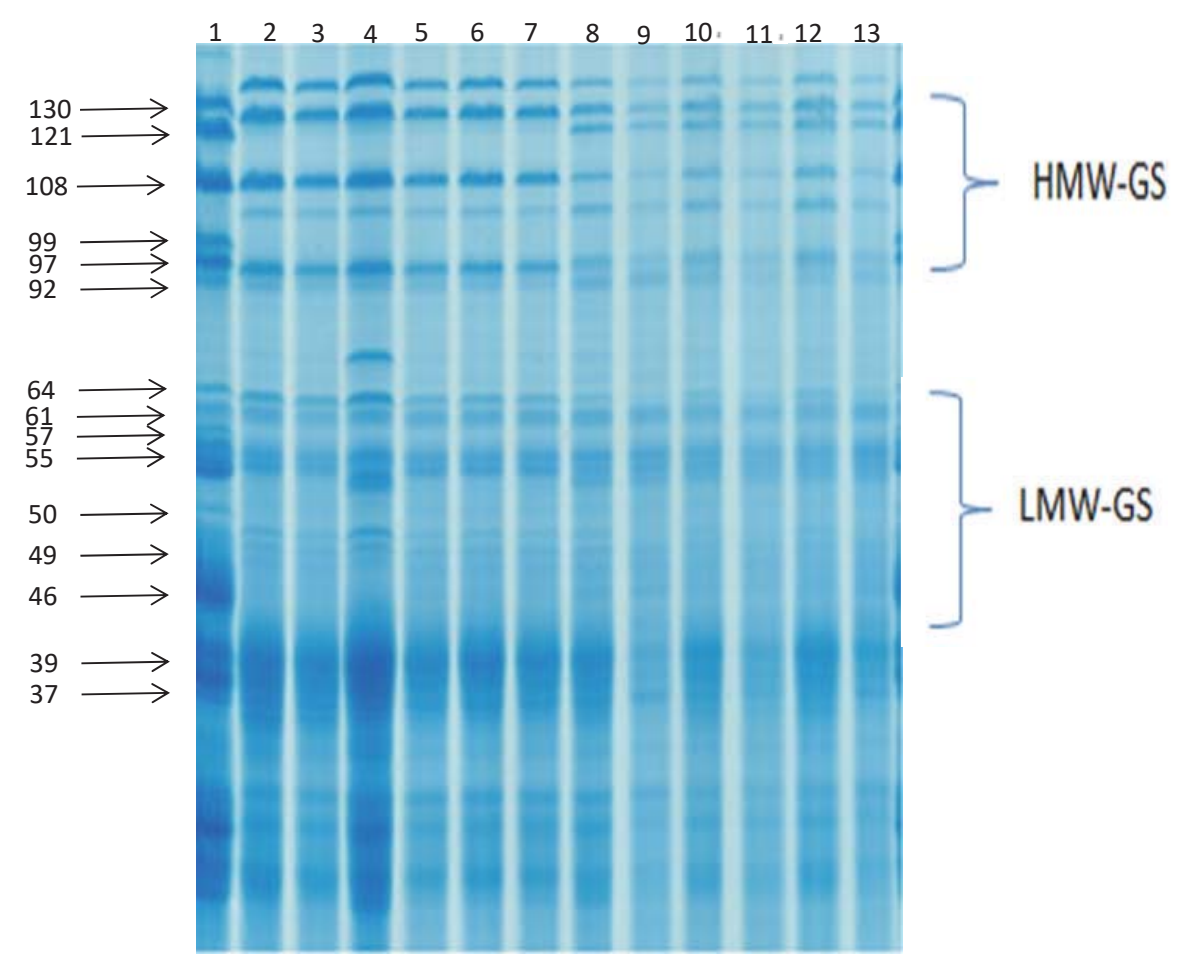

Fig. 2. Effect of SD1 on glutenin bands of SWF and HPAWF

SWF: Sound wheat flour (SWF); HPAWF: high protease activity wheat flour $(50 \% \mathrm{SWF}+50 \%$ suni-bug damaged flour);

1: Katepwa; 2: SWF; 3: SWF after fermentation, 4: SWF $+20 \%$ SD1; $5:$ SWF $+20 \%$ SD1 after fermentation, 6: 40\% SD1; 7: 40\% SD1 after fermentation; 8: HPAWF; 9: HPAWF after fermentation; 10: 20\% SD1 + HPAWF; 11: 20\% SD1 + HPAWF after fermentation, 12: 40\% SD1 + HPAWF; 13: 40\% SD1 + HPAWF after fermentation 
Decreasing the intensities of glutenin bands of HPAWF after 2 hours of fermentation indicated proteolytic activity (Fig. 2, lines 8 and 9). No change was observed in the intensities of glutenin bands for $20 \%$ sourdough addition, while they increased with the addition of $40 \%$ sourdough (Fig. 2, lines 9 and 13). These results demonstrated that $40 \%$ sourdough $(L$. plantarum) addition inhibited suni-bug protease.

\subsection{Effect of sourdough prepared from $\mathrm{L}$. sanfranciscensis on electrophoretic patterns of glutenins}

Sourdough prepared with $L$. sanfranciscensis had no hydrolysing effect on glutenin bands of sound wheat flour after fermentation (Fig. 3, line 3, 5 and 7) (DI CAGNO et al. 2002, VERMEULEN et al. 2005). SDS-PAGE results of SD2 (L. sanfranciscensis) were similar to those of SD1 (L. plantarum) to some extent.

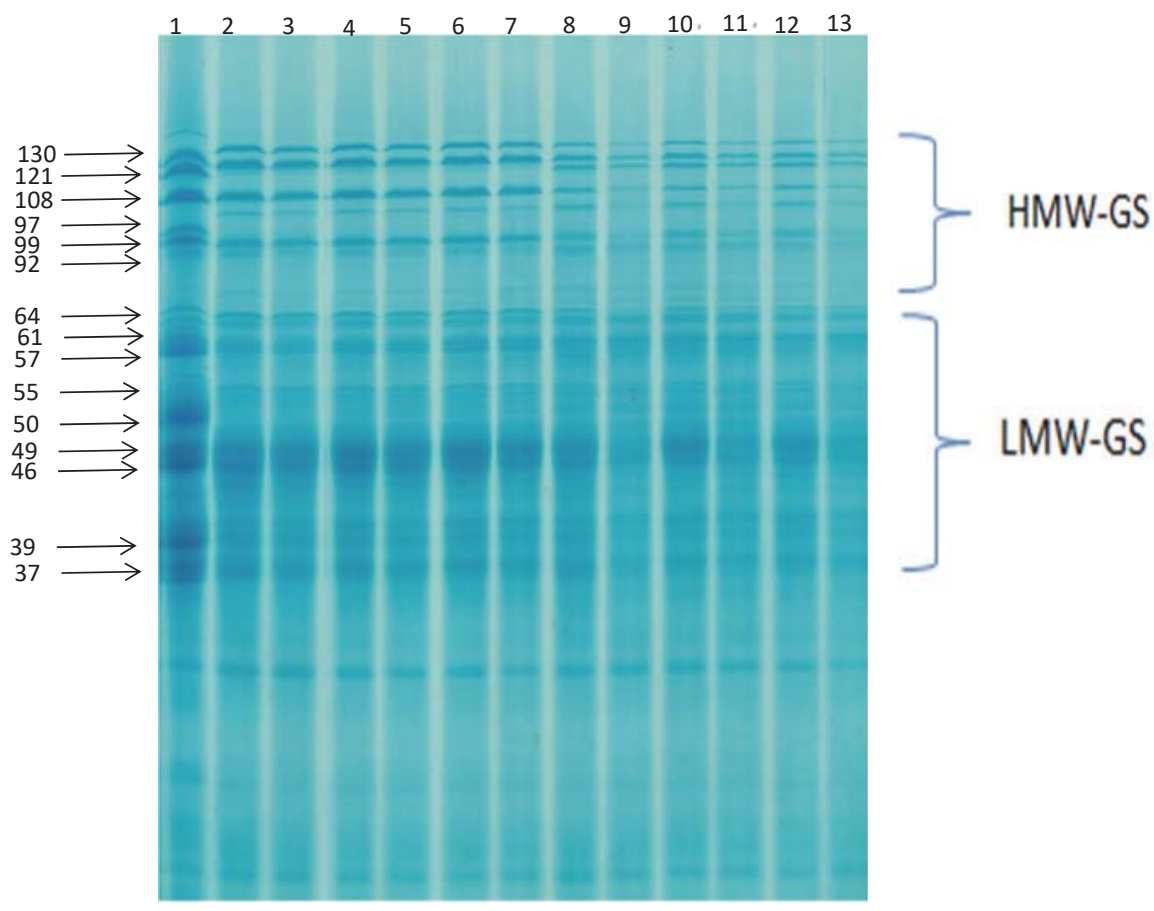

Fig. 3. Effect of SD2 on glutenin bands of SWF and HPAWF

SWF: sound wheat flour (SWF); HPAWF: high protease activity wheat flour $(50 \% \mathrm{SWF}+50 \%$ suni-bug damaged flour);

1: Katepwa; 2: SWF; 3: SWF after fermentation; 4: 20\% SD2 + HPAWF; 5: 20\% SD2 + HPAWF after fermentation; 6: 40\% SD2 + HPAWF; 7: 40\% SD2 + HPAWF after fermentation; 8: HPAWF; 9: HPAWF after fermentation; 10: 20\% SD2 + HPAWF; 11: 20\% SD2 + HPAWF after fermentation; 12: 40\% SD2 + HPAWF; 13: $40 \%$ SD2 + HPAWF after fermentation.

Sourdough addition at the level of $20 \%$ to HPAWF slightly increased the intensities of the glutenin bands, suggesting that proteolytic activity has been inactivated (Fig. 2, lines 9 and 11). No proteolytic activity was detected for $40 \%$ SD2 addition to HPAWF (Fig. 2, lines 9 and 13). 


\subsection{Effect of liquid rye sour on electrophoretic patterns of glutenins}

There was no effect of 1 and $2 \%$ liquid rye sour (LRS) addition to sound wheat flour (control) on glutenin patterns. However, the proteolytic activity of HPAWF was inhibited by LRS addition at both levels (Fig. 4, lines 9, 11, and 13).

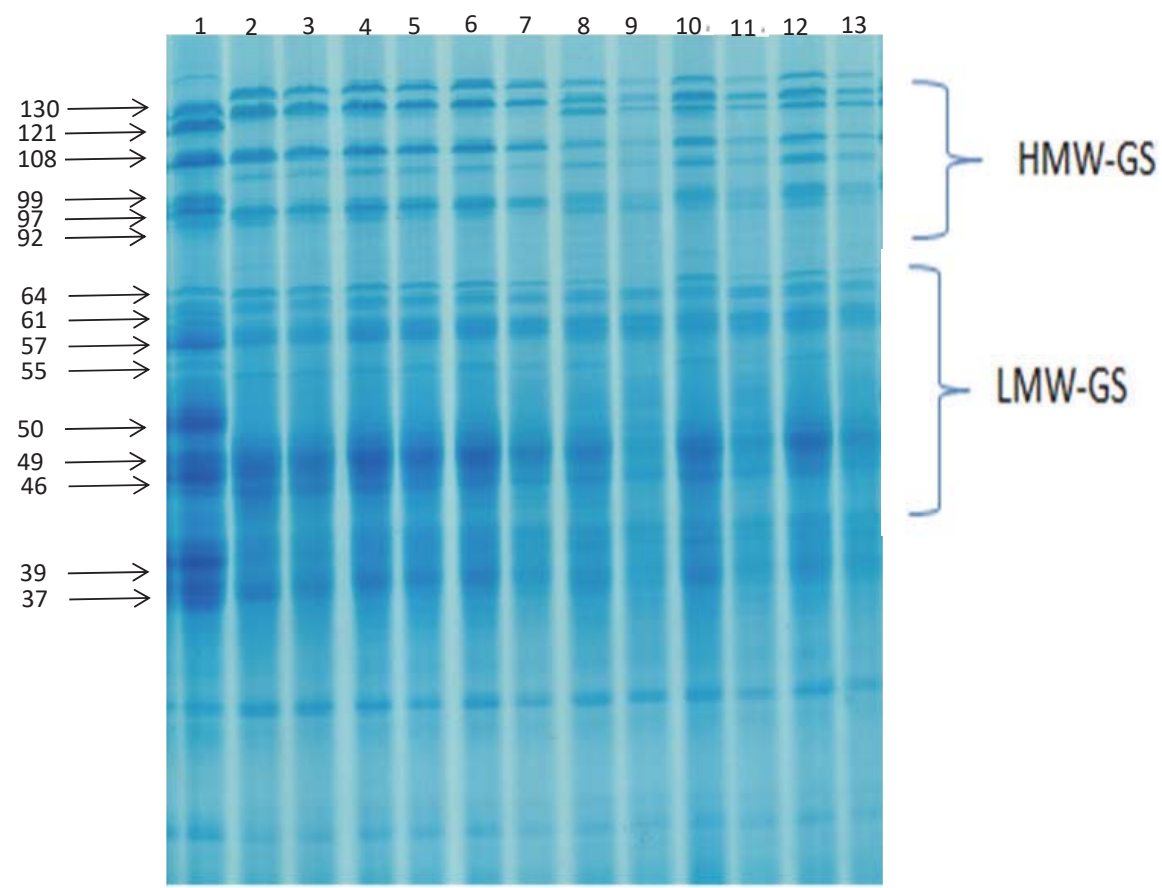

Fig. 4. Effect of LRS on glutenin bands of SWF and 50\% HPAWF

SWF: sound wheat flour (SWF); HPAWF: high protease activity wheat flour $(50 \% \mathrm{SWF}+50 \%$ suni-bug damaged flour)

1: Katepwa; 2: SWF; 3: SWF after fermentation; 4: 1\% LRS + SWF; 5: 1\% LRS + SWF after fermentation; 6: $2 \%$ LRS + SWF; 7: 2\% LRS + SWF after fermentation; 8: HPAWF; 9: HPAWF after fermentation; 10: $1 \%$ LRS + HPAWF; 11: 1\% LRS + HPAWF after fermentation; 12: 2\% LRS + HPAWF; 13: $2 \%$ LRS + HPAWF after fermentation

\subsection{Effect of sourdough and liquid rye sour on bread quality}

According to the SDS-PAGE results, the applications resulting low protease activity $(40 \%$ SD1, 20\% SD2, and 1 and $2 \%$ of LRS) were used in the baking experiments of both HPAWF and LPAWF.

Effects of addition of SD1 (40\%), LRS (2\%), and SD2 (20\%) on volume, hardness, crumb and crust colour are shown in Table 2A. As expected, the volume of the HPAWF (317 $\mathrm{cm}^{3}$ ) was lower than that of control $\left(432 \mathrm{~cm}^{3}\right)$ (Table 2A). LRS addition (2\%) increased bread volume significantly $(\mathrm{P}<0.05)$ (Table 2 and Fig. 5), providing higher bread volume than the other treatments ( $1 \%$ LRS, $40 \%$ SD1, and $20 \%$ SD2). No significant effect on volume and hardness values was observed with the addition of $40 \%$ SD1 and $20 \%$ SD2, but the bread with an additional 2\% LRS was comparable with the control sample (SWF) (Table 2A). 
Table 2. Quality characteristics of HPAWF and LPAWF breads ${ }^{1}$

\begin{tabular}{lccccccc}
\hline SAMPLE & \multicolumn{3}{c}{ Crust colour $^{2}$} & \multicolumn{2}{c}{ Crumb colour $^{2}$} \\
\cline { 2 - 9 } & $\begin{array}{c}\text { Volume } \\
\left(\mathrm{cm}^{3}\right)\end{array}$ & $\begin{array}{c}\text { Specific } \\
\text { volume } \\
\left(\mathrm{cm}^{3} \mathrm{~g}^{-1}\right)\end{array}$ & $\begin{array}{c}\text { Hardness } \\
(\mathrm{N})\end{array}$ & $L^{*}$ & $a^{*}$ & $L^{*}$ & $b^{*}$ \\
\hline A) & $432^{\mathrm{a}}$ & $3.21^{\mathrm{a}}$ & $4.55^{\mathrm{c}}$ & $53.00^{\mathrm{d}}$ & $13.01^{\mathrm{a}}$ & $61.11^{\mathrm{cd}}$ & $14.16^{\mathrm{a}}$ \\
SWF & $317^{\mathrm{d}}$ & $2.45^{\mathrm{cd}}$ & $7.37^{\mathrm{b}}$ & $46.42^{\mathrm{e}}$ & $7.21^{\mathrm{c}}$ & $50.71^{\mathrm{f}}$ & $13.72^{\mathrm{a}}$ \\
HPAWF & $351^{\mathrm{c}}$ & $2.67^{\mathrm{c}}$ & $7.38^{\mathrm{b}}$ & $58.66^{\mathrm{ab}}$ & $10.61^{\mathrm{b}}$ & $65.68^{\mathrm{b}}$ & $14.50^{\mathrm{a}}$ \\
HPAWF+ 1\% LRS & $388^{\mathrm{b}}$ & $2.95^{\mathrm{b}}$ & $6.81^{\mathrm{b}}$ & $62.48^{\mathrm{a}}$ & $10.08^{\mathrm{b}}$ & $70.93^{\mathrm{a}}$ & $14.50^{\mathrm{a}}$ \\
HPAWF+ 2\% LRS & $301^{\mathrm{d}}$ & $2.32^{\mathrm{d}}$ & $8.33^{\mathrm{a}}$ & $61.76^{\mathrm{a}}$ & $8.01^{\mathrm{c}}$ & $57.19^{\mathrm{de}}$ & $13.92^{\mathrm{a}}$ \\
HPAWF+ 40\% SD1 & $307^{\mathrm{d}}$ & $2.39^{\mathrm{d}}$ & $8.87^{\mathrm{a}}$ & $58.75^{\mathrm{ab}}$ & $7.53^{\mathrm{c}}$ & $63.6^{\mathrm{bc}}$ & $13.62^{\mathrm{a}}$ \\
\hline HPAWF+ 20\% SD2 & & & & & & & \\
\hline B) & $432^{\mathrm{b}}$ & $3.21^{\mathrm{b}}$ & $4.55^{\mathrm{c}}$ & $53.00^{\mathrm{a}}$ & $13.01^{\mathrm{a}}$ & $61.11^{\mathrm{a}}$ & $14.16^{\mathrm{a}}$ \\
\hline SWF & $393^{\mathrm{c}}$ & $2.97^{\mathrm{c}}$ & $6.41^{\mathrm{b}}$ & $51.29^{\mathrm{a}}$ & $10.13^{\mathrm{b}}$ & $57.04^{\mathrm{ab}}$ & $13.98^{\mathrm{a}}$ \\
LPAWF & $464^{\mathrm{a}}$ & $3.54^{\mathrm{a}}$ & $2.84^{\mathrm{d}}$ & $56.20^{\mathrm{a}}$ & $13.72^{\mathrm{a}}$ & $61.17^{\mathrm{a}}$ & $13.06^{\mathrm{a}}$ \\
LPAWF+ 2\% LRS & $357^{\mathrm{d}}$ & $2.72^{\mathrm{d}}$ & $8.72^{\mathrm{a}}$ & $52.57^{\mathrm{a}}$ & $10.74^{\mathrm{b}}$ & $59.32^{\mathrm{ab}}$ & $13.79^{\mathrm{a}}$ \\
LPAWF+ 40\% SD1 & $394^{\mathrm{c}}$ & $2.97^{\mathrm{c}}$ & $6.56^{\mathrm{b}}$ & $51.83^{\mathrm{a}}$ & $10.42^{\mathrm{b}}$ & $54.93^{\mathrm{b}}$ & $13.67^{\mathrm{a}}$ \\
LPAWF+ 40\% SD2 & & & & & & & \\
\hline
\end{tabular}

${ }^{1}$ : Mean values followed by different letters are significantly different at $\mathrm{P}<0.05 ;{ }^{2}$ : all values are average of two parellel breads; SWF: sound wheat flour; HPAWF: high protease activity wheat flour $(50 \% \mathrm{SWF}+50 \%$ suni-bug damaged flour); LPAWF: Low protease activity wheat flour $(75 \% \mathrm{SWF}+25 \%$ suni-bug damaged flour); LRS: liquid rye sour; SD1: sourdough prepared with L.plantarum; SD2: sourdough prepared with L. sanfrancissensis

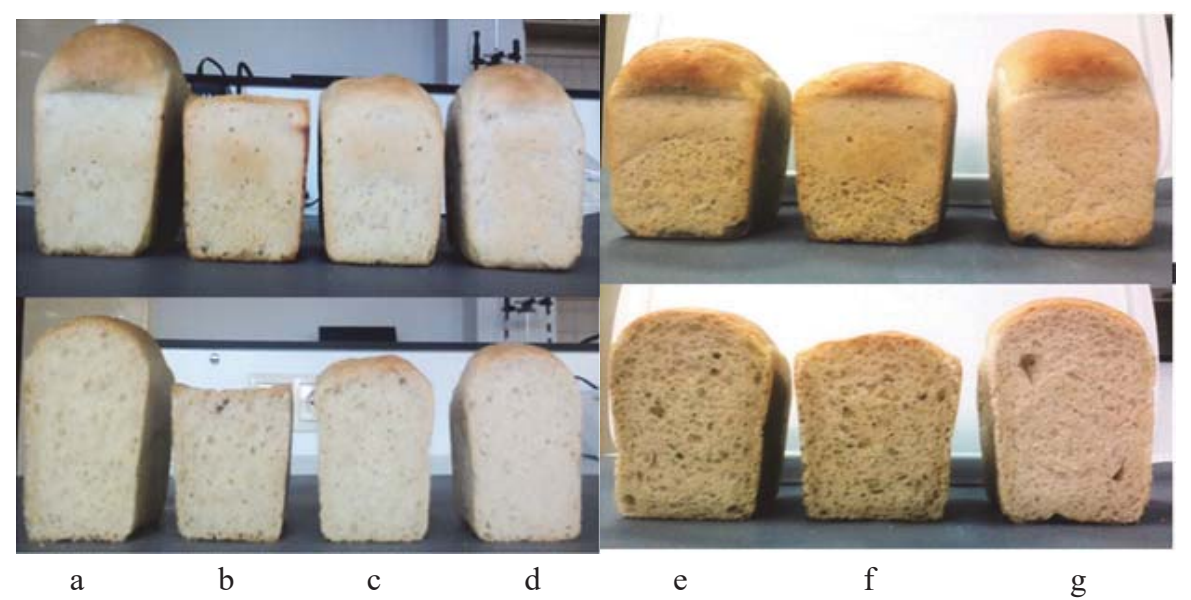

Fig. 5. External appearance and crumb structure of LRS addition to HPAWF and LPAWF breads LRS: liquid rye sour; HPAWF: high protease activity wheat flour; LPAWF : low protease activity wheat flour a: control; b: HPAWF bread; c: HPAWF + 1\% LRS bread; d: HPAWF + $2 \%$ LRS bread; e: control; f: LPAWF bread; g: LPAWF + 2\% LRS bread

LRS $(2 \%)$ and SD1 (40\%) additions caused increase in the $L^{*}$ (Lightness) values, indicating brighter crust colour (Table 2A). $a^{*}$ values of bread were lower compared to control bread. LRS addition caused significant increase in $a^{*}$ values, but addition levels 
(1 and 2\%) had no significant effect. Other additions (40\% SD1 and 20\% SD2) did not affect $a^{*}$ values of the bread crust $(\mathrm{P}<0.05)$ (Table $\left.2 \mathrm{~A}\right)$.

The $L^{*}$ value of the crumb also increased with the addition of LRS and SD. Higher $L^{*}$ values of the crumb were observed with increasing LRS levels $(\mathrm{P}<0.05)$. Highest redness $\left(a^{*}\right)$ value of the crumb was measured for $40 \%$ SD1 addition, and there was no significant change in yellowness $\left(b^{*}\right)$ values for any samples $(\mathrm{P}<0.05)$ (Table $\left.2 \mathrm{~A}\right)$.

SIVRI and KöKSEL (2002) reported that bread additives such as ascorbic acid, DATEM and vital gluten had an improving effect on bread quality made from bug-damaged flour. However, these additives had no effect on the bread quality when the wheat was damaged at high levels. To confirm this, SD (40\%) and LRS (2\%) were also tried for LPAWF (Table 2B). LRS addition at the $2 \%$ level gave better results in terms of bread characteristics (Fig. 5). As compared to the control sample, higher bread volume and lower hardness values were obtained (Table $2 \mathrm{~B}$ ). $L^{*}$ values of the crust were comparable. Addition of $2 \%$ LRS resulted in the highest $a^{*}$ value of the crust and $L^{*}$ value of the crumb (Table 2B). It is well known that sourdough bread making has a positive effect on texture, shelf life, and aroma of breads, but there are also some related health issues such as gluten-free bread making (Moroni et al., 2009; TORRIERI et al., 2014). In this study, although 40\% SD1 and 20\% SD2 sourdough addition to HPAWF resulted in lower protease activity as expected, using sourdoughs had no detectable effect on bread quality. The effects of liquid rye sour were more obvious on bread quality for HPAWF. It can be concluded that addition of lactic acid bacteria and liquid rye sour could be a tool to improve the bread quality of suni-bug damaged wheat flours at low damage levels.

\section{Conclusions}

Bug damage to wheat causes serious economical losses in some countries. Many modifications were tried in the breadmaking process to overcome this problem. Decreasing the $\mathrm{pH}$ of the dough could be one of them, because the activity of bug protease at acidic $\mathrm{pH}$ is relatively low (SIVRI \& KöKSEL, 2002). This is the first report on the utilisation of sourdough, an ancient technology, in breadmaking with bug damaged wheat flour. Although SDS PAGE results showed that proteolytic activity of HPAWF decreased by addition of sourdough, no positive effect of sourdough addition was observed on the bread properties, especially volume and texture. On the other hand, liquid rye sour application had positive effect on breadmaking quality of HPAWF. It can be concluded that lactic acid bacteria and liquid rye sour can be used to improve the bread quality of suni-bug affected flours at low damage levels.

The authors would like to thank Field Crops Central Research Institute, Ankara (Turkey); Plant Protection Research Station, Diyarbakır (Turkey); Ireks Food Industry (Turkey) for supplying research materials.

\section{References}

AACC (1990): American Association of Cereal Chemists International AACC (2000): American Association of Cereal Chemists International AACC (2010): American Association of Cereal Chemists International Arendt, E., Ryan, L.A.M. \& Dal Bello, F. (2007): Impact of sourdough on the texture of bread. Food Microbiol., $24,165-174$. 
DeCock, P. \& Cappelle, S. (2005): Bread technology and sourdough technology. Trends Food Sci. Tech., 16, 113120.

Di Cagno, R., De Angelis, M., Lavermiccocca, P., De Vincenzi, M., Giovanni, C., ... \& Gobbetti, M. (2002): Proteolysis by sourdough lactic acid bacteria: Effects on wheat flour protein fractions and gliadin peptides involved in human cereal intolerance. Appl. Environ. Microb., 68, 623-633.

Diraman, H., BoyacioĞLu, M. \& AtLı, A. (1998): Buğday ve unlarda süne zararına karşı alınacak önlemler. (Precautions against the suni-bug damage of wheat and flour). Pasta Ekmek Dondurma ve Teknik., 2, 46-48.

Diraman, H. \& Demirci, M. (1997): Süne hasarlı unlarda 1sıl işlemin ve bazı katkıların gluten kalitesi üzerine etkileri. (Effects of heat treatment and some additives on gluten quality of suni-bug damaged flour). Un Mamülleri Dünyası., 6, 4-11.

Fu, B. \& SAPIRSTEIN, H. (1996): Procedure for isolating monomeric proteins and polymeric glutenin of wheat flour. Cereal Chem., 73, 143-152.

Gobbetti, M., De Angelis, M., Corsetti, A. \& Di Cagno, R. (2005): Biochemistry and physiology of sourdough lactic acid bacteria. Trends Food Sci. Tech., 16, 57-69.

KARABABA, E. \& OZAN, A. (1998): Effect of wheat bug (Eurygaster integriceps) damage on quality of a wheat variety grown in Turkey. J. Sci. Food Agr., 77, 399-403.

Koksel, H., Kahraman, K., Sanal, T., Sivri Ozay, D. \& Dubat, A. (2009): Potential utilization of mixolab for quality evaluation of bread wheat genotypes. Cereal Chem., 86, 522-526.

KöKSEL, H., ATLI, A., DAĞ, A. \& SIVRI, D. (2002): Commercial milling of suni bug (Eurygaster spp.) damaged wheat. Nahrung, 46, 25-27.

Moroni, A., DAL Bello, F. \& ARENdt, E. (2009): Sourdough in gluten-free bread-making: An ancient technology to solve a novel issue. Food Microbiol., 26, 676-684.

NG, P. \& BushuK, W. (1987): Glutenin of Marquis wheat as a reference for estimating molecular weights of glutenin subunits by sodium dodecyl sulfate polyacrylamide gel electrophoresis. Cereal Chem., 64, 324-335.

OlanCA, B. \& SivRi ÖZAY, D. (2015): Effects of natural inhibitors on high activity flours. J. Cereal Sci., 65, 290-297.

SIVRI, D. \& KöKSEL, H. (2000): Characterisation and partial purification of gluten hydrolyzing protease from bug (Eurygaster spp.) damaged wheat. -in: ShewrY, P.R. \& TAтHAM, A.S. (Eds) Wheat gluten. Royal Society of Chemistry, Cambridge, UK. pp. 287-290.

SIVRI, D. \& KöKSEL, H. (2002): Süne zararı görmüş buğdaylarda proteaz enziminin İnaktivasyonu ve bazı unlu mamüllerde kullanılabilme olanaklarının araştırılması. TÜBİTAK Proje No: TARP-2289, Ankara. (Inactivation of protease enzyme in suni-damaged wheat and investigation of its possibilities in some bakery products. TÜBİTAK Project No: TARP-2289, Ankara.)

Torrieri, E., Pepe, O., Ventorino, V., Masi, P. \& CaVella, S. (2014): Effect of sourdough at different concentrations on quality and shelf life of bread. LWT - Food Sci. Technol., 56, 508-516.

Vermeulen, N., Pavlovic, M., Ehrmann, M.A., Gänzle, M.G. \& Vogel, R.F. (2005): Functional characterization of the proteolytic system of Lactobacillus sanfranciscensis DSM 20451T during growth in sourdough. Appl. Environ. Microb., 71, 6260-6266.

Wehrle, K., Crowe, N., van Boeijen, I. \& Arendt, E. (1999): Screening methods for the proteolytic breakdown of gluten by lactic acid bacteria and enzyme preparations. Eur. Food Res. Technol., 209, 428-433. 